\title{
Epidemiology and prevention of hypertension in Japanese: how could Japan get longevity?
}

\author{
Katsuyuki Miura
}

Received: 30 December 2010 / Accepted: 28 February 2011 /Published online: 18 March 2011

(C) European Association for Predictive, Preventive and Personalised Medicine 2011

\begin{abstract}
Japan is one of the countries with the longest longevity in the world, and it was accomplished by a drastic decline in stroke mortality from 1960's. The decline in stroke mortality would be largely explained by a population-wide decreasing trend in blood pressure (BP) level, because higher BP has been the strongest risk factor of stroke; about $20 \%$ of total deaths can be explained by higher BP above optimal in Japan. Decreasing trend in BP occurred both in men and women in all age-groups, which cannot be fully explained by the widespread use of anti-hypertensive agents. The most probable reason for the population-wide BP decline in Japan would be a large decline in dietary salt intake after 1950's. However, other factors including obesity, high alcohol intake, and unfavorable dietary habits could increase BP level of Japanese again.
\end{abstract}

Keywords Blood pressure · Hypertension · Epidemiology · Prevention · Japan

\section{Introduction}

Hypertension has been acknowledged as one of the greatest and established risk factors for cardiovascular diseases (CVD) (heart diseases and stroke) [1-4]. Particularly in East Asian countries, where the mortality and morbidity of stroke have been higher than in western countries, measures against hypertension are considered very important in the

K. Miura $(\bowtie)$

Department of Health Science,

Shiga University of Medical Science,

Seta-Tsukinowa-cho,

Otsu, Shiga 520-2192, Japan

e-mail: miura@belle.shiga-med.ac.jp prevention of stroke. Hypertension affects a majority of the elderly, and drug therapies for hypertension have greatly added to medical costs in most developed countries. On the other hand, Japan is one of the countries with the longest longevity in the world, the major reason of which is regarded to be a great decline in stroke mortality due to a decrease in nationwide blood pressure (BP) levels [5].

The author has been involved in epidemiological researches on the risk assessment and prevention of hypertension through several cohort studies in Japan, their meta-analyses, and international cooperative studies. In this article, findings from these studies are reviewed from the viewpoints of population-wide and individual-based preventive approaches in Japanese, and the reason of the longest longevity of Japanese is discussed.

\section{Cardiovascular risk by high blood pressure in Japanese}

The National Integrated Project for Prospective Observation of Non-communicable Disease and Its Trends in the Aged (NIPPON DATA) consists of two cohort studies of representative Japanese population samples who participated in the National Surveys on Circulatory Disorders and the National Nutrition Surveys in 1980 (NIPPON DATA80) and in 1990 (NIPPON DATA90). A total of approximately 10,000 (NIPPON DATA80) and 8,000 (NIPPON DATA90) participants were from 300 randomly selected areas from all over Japan. This project has served a number of evidences on the relationships of major CVD risk factors on long-term CVD mortality risk [6], including a strong, continuous, graded, and independent relationship of BP levels to CVD risk [7, 8]. In addition, follow-up surveys on activity of daily living (ADL) in the NIPPON DATA80 participants reported a positive 
relation between high $\mathrm{BP}$ at middle age and future impaired ADL, since a large part of impaired ADL is caused by stroke occurrence in Japan [9]. We found that $45 \%$ of impaired ADL could be explained by non-normal BP at baseline.

The Evidence for Cardiovascular Prevention from Observational Cohorts in Japan (EPOCH-JAPAN) is a meta-analysis of individual participants' data from highquality established 13 cohort studies in Japan, including NIPPON DATA. The total number of EPOCH-JAPAN participants was over 180 thousands, with approximately 10 years of follow-up, and sex- and age-specific risks (relative and attributable) of all-cause mortality with higher BP were estimated in this meta-analysis [10]. Adjusted allcause mortality increased as BP increased in all age-groups (Fig. 1), and this trend was more apparent in younger people than older people; hazard ratio [HR] for $10 \mathrm{~mm} \mathrm{Hg}$ increase in systolic BP was 1.37 in men aged 40-49, whereas HR was 1.09 in men aged $80-89$. Younger people should pay more attention to BP increase to prevent future cardiovascular risk, and should modify their lifestyle to lower BP from their younger age. Moreover, populationattributable fraction of deaths with higher BP above optimal $(<120 / 80 \mathrm{~mm} \mathrm{Hg})$ was $23 \%$ in men and $18 \%$ in women.

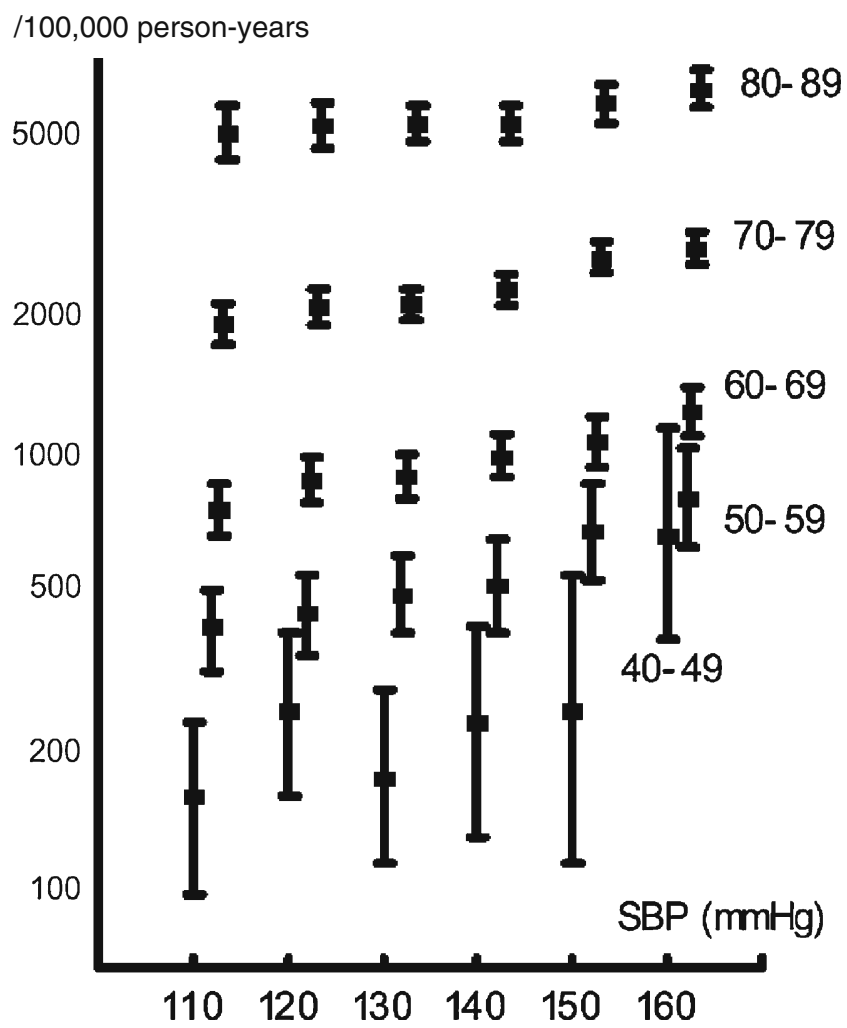

Fig. 1 Relation between blood pressure and multivariate-adjusted mortality rate by age range (men and women combined). Each dot represents a multivariate estimate of mortality rate after adjusting for sex, smoking, drinking, and body mass index, and each line shows the $95 \%$ CI $[10]$
Thus, a great impact of higher BP above optimal level on total deaths in Japan was revealed.

Some epidemiologic studies reported that pulse pressure (PP), the difference between systolic BP (SBP) and diastolic BP (DBP), is a useful predictor for CVD especially in middleaged or older people [11, 12]; however, it was uncertain whether PP is superior to SBP or DBP in predicting future CVD risk in various age-sex groups of general Japanese population, where stroke is dominant among CVDs. Moreover, it is also important to assess whether DBP has any additional role in predicting risks independently from SBP. The author examined these questions in a population-based cohort study, the Oyabe Study, on long-term stroke incidence by four age-sex groups (men and women aged 35-64 and 65-79 years) [13]. The study showed that relations of PP to stroke risk were less strong than those of SBP in all age-sex groups. In middle-aged men, the strongest relationship to stroke incidence was observed for DBP (HR 1.79 for 1 standard deviation $[\mathrm{SD}]$ increase). In older men, the strongest relationship to stroke risk was observed for SBP (HR 1.62). In middle-aged and older women, both SBP (HR 1.56 and 2.25 ) and DBP (HR 1.63 and 2.46) showed similarly strong relationships to stroke risk.

This issue was also examined by large-scale metaanalyses [3, 14]. However, the majority of study participants in these studies were Caucasians (even in one study from the Asia Pacific region), and there have been few investigations including only Asian people. Moreover, it was still uncertain whether the importance of BP indices differs for predicting ischemic stroke and hemorrhagic stroke risks. The Japan Arteriosclerosis Longitudinal Study-Existing Cohorts Combine (JALS-ECC) is a pooling project based on individual participant data from existing high-quality prospective cohort studies on CVD in Japan [15]. From this project, the author reported the metaanalysis of 16 cohort studies which allowed detailed investigations with over 1,000 stroke events and 200 myocardial infarction (MI) events from over 400,000 person-years of follow-up in Japanese [16]. Stroke risk was most strongly related to mean BP (MBP) and SBP in both sexes, and was most weakly related to PP (Fig. 2). SBP and DBP were independently and positively related to stroke risk in both sexes, even after adjusted for each other. Both stroke subtypes, ischemic and hemorrhagic, were most strongly related to MBP or SBP in both sexes. Also in older men and women aged 70-89, MBP or SBP showed the strongest relation to all stroke risk. MI risk was most strongly related to SBP and MBP in both sexes. For any CVD endpoints in any age-sex groups, PP was not the strongest predictor. In this report, we concluded that the long-term incident risk of stroke and MI associated with high BP in East Asian populations should be assessed mainly on the basis of SBP. 

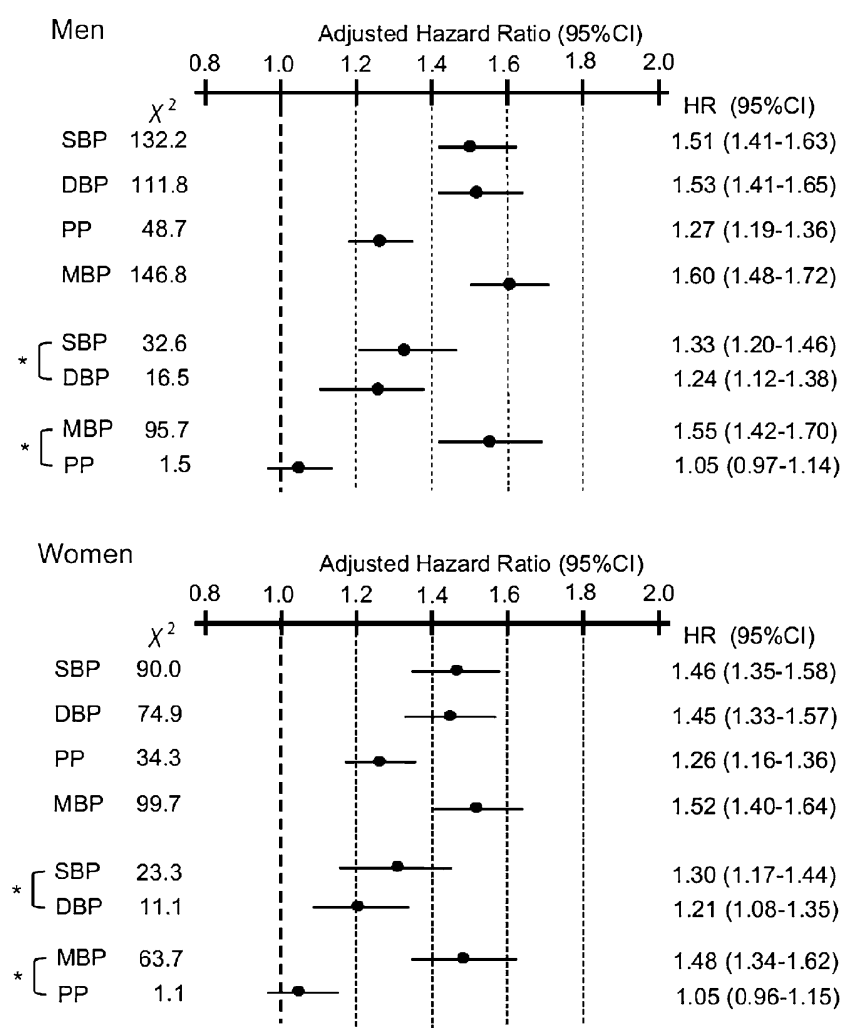

Fig. 2 Adjusted hazard ratios for four blood pressure indexes for all stroke incidence by sex. Hazard ratios are calculated for each BP index higher by 1 standard deviation, and adjusted for age, body mass index, total cholesterol, and smoking using Poisson regression [16]. * Two BP indices are included in the same model. $S B P$ systolic blood pressure; $D B P$ diastolic blood pressure; $P P$ pulse pressure; $M B P$ mean blood pressure; $H R$ hazard ratio; $95 \% C I 95 \%$ confidence interval

\section{Factors related to blood pressure in Japan}

Several factors have been reported to determine populationwide BP level and individual's BP in Japan. In 1960, Dahl authored a famous study on the relationship between salt intake and BP in populations in various parts of the world, including Japan [17]. He reported that people living in northern Japan consumed about $30 \mathrm{~g}$ salt per day and had an almost $40 \%$ prevalence of hypertension, whereas Alaskan natives consumed less than $5 \mathrm{~g}$ of salt per day and had a prevalence of almost zero. However, this study was not standardized for BP determinations and dietetic investigations. The INTERSALT study was conducted, using 52 populations in 32 countries (including three populations in Japan) (a total of 10,079 participants), with strictly standardized BP measurement and evaluation of salt intake by 24-h urinary sodium excretion determination [1820]. The INTERSALT study found that urinary sodium excretion was significantly related to individual BP and to age-dependent BP elevation, after adjustment for age, gender, obesity and alcohol consumption. It was estimated that $100 \mathrm{mmol}$ lower sodium excretion (equivalent to about $6 \mathrm{~g}$ salt) was related to $2.2 \mathrm{mmHg}$ lower SBP, and to lower elevation in SBP and DBP by $10-11 \mathrm{mmHg}$ and $6 \mathrm{mmHg}$, respectively, between 25 and 55 years of age - a period of 30 years. As also mentioned below, salt intake would be surely related to BP level in Japanese.

The INTERSALT study also showed that SBP was significantly higher in men and women drinking $\geq 300 \mathrm{ml}$ of ethanol/week (approximately $238 \mathrm{~g}$ ) than in non-drinkers [21]. Other cross-sectional studies in Japanese men showed that SBP was approximately $7-10 \mathrm{mmHg}$ higher, and DBP was approximately $2-7 \mathrm{mmHg}$ higher, in drinkers of three to six drinks/day (approximately 210-420 g of ethanol/week) than in non-drinkers [22, 23], and that the relationship was not different among the types of beverage [24]. Moreover, a large-scale 7-year follow-up study of Japanese male workers revealed that, when adjusted for age, weight change, and foods intake, average annual increases in SBP were $0.33 \mathrm{~mm}$ $\mathrm{Hg}$ greater in drinkers of $\geq 300 \mathrm{~g}$ ethanol/week than in nondrinkers; it means that SBP in drinkers will increase $3.3 \mathrm{~mm}$ $\mathrm{Hg}$ greater in 10 years than in non-drinkers [25]. A randomized controlled trial in Japanese habitual male drinkers also showed that a reduction of ethanol consumption from $56 \mathrm{ml} /$ day to $23 \mathrm{ml} /$ day resulted in $3.6 \mathrm{~mm} \mathrm{Hg}$ decrease in SBP [26]. The International Study of MacroMicro-nutrients and Blood Pressure (INTERMAP) showed that mean ethanol intake in middle-aged men was the highest in Japan (30 g/day) among four countries, whereas it was $20 \mathrm{~g} /$ day in the UK, $17 \mathrm{~g} /$ day in China, and $11 \mathrm{~g} /$ day in the USA [27]. Therefore, higher alcohol consumption would contribute largely to increase BP level and the prevalence of hypertension in Japanese men.

The INTERMAP is an international cross-sectional epidemiologic study of 4,680 men and women ages 40-59 from 17 population samples in China (three samples), Japan (four samples), UK (two samples), and USA (eight samples). Nutrient intake data were based on four in-depth multi-pass 24-h dietary recalls/person and two timed 24-h urine collection/person, and BP was measured eight times at four visits $[28,29]$. The study has reported the relationships of several nutrients to $\mathrm{BP}$, including the intakes of vegetable protein, omega-3 polyunsaturated fatty acids (PFA), omega-6 PFA (linoleic acid), dietary cholesterol, phosphorus, non-heme iron, and glutamic acid [30-36]. Among these nutrients, omega-3 PFA intake, which was inversely related to BP, was the highest in Japan among four countries (3.4 g/day in men and $2.7 \mathrm{~g} /$ day in women) due to higher fish intake [31], so that higher omega-3 PFA intake would affect favorably to BP level in Japanese. On the other hand, dietary cholesterol intake, which was positively related to BP, was the highest in Japan (446 mg/day in men and $359 \mathrm{mg} /$ day in women) largely due to higher egg intake [33], so that higher cholesterol intake would affect unfavorably to BP level in Japanese. 
Fig. 3 Trend in age-adjusted mortality rate $(/ 100,000)$ of stroke in Japan by sex and stroke subtypes, the Vital Statistics of Japan (1950-2008). CI cerebral infarction; $\mathrm{CH}$ cerebral hemorrhage; $S A H$ subarachnoid hemorrhage

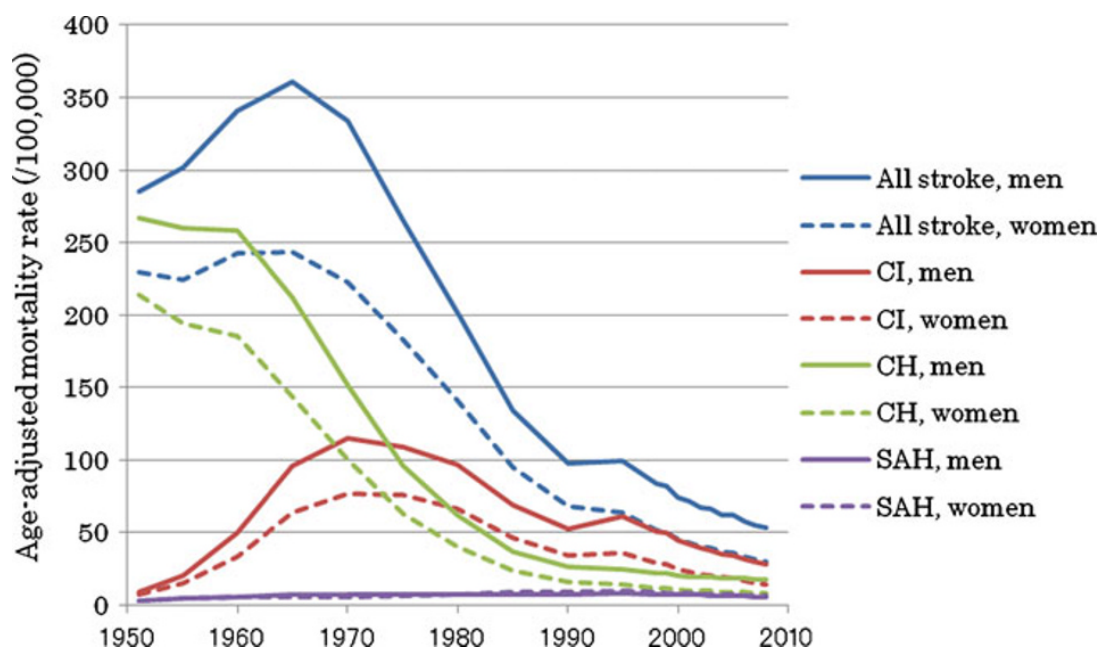

Obesity is, of course, an important factor for high BP in Japanese, although Japanese people have been relatively lean compared with western people. The proportion of individuals with obesity-induced hypertension among total hypertensives was calculated using the baseline data of NIPPON DATA80 and NIPPON DATA90 [37]. The estimated percentage whose hypertension was attributed by obesity $\left(\mathrm{BMI} \geq 25 \mathrm{~kg} / \mathrm{m}^{2}\right)$ in 1980 and 1990 was $11 \%$ and $15 \%$ for men and $19 \%$ and $22 \%$ for women, respectively. Thus, obesity-induced hypertension increased between 1980 and 1990 for both sexes. As the proportion of obesity has been increasing continuously in men and in older women in Japan, these percentages would be higher now compared with those in 1980 and 1990.

\section{Decline in blood pressure and stroke mortality in Japan}

During 1960's, mortality due to stroke in the Japanese population was markedly high by international standards, but has now been drastically reduced to approximately oneseventh of the previous level (Fig. 3). This drastic change is the main cause of elongation in longevity of Japanese during the past several decades, and it is presumably largely due to a steady decrease in the mean BP of the population. This decrease in BP was not only found in the elderly, but also in the middle-aged and younger generations. The National Survey on Circulatory Disorders of Japan showed that in the 30 years from 1971 to 2000, the mean SBP for Japanese men aged 40 to 49 decreased by $3.6 \mathrm{mmHg}$, from $134.8 \mathrm{mmHg}$ to $131.2 \mathrm{mmHg}$, and for women aged 40 to 49 it decreased by $7.7 \mathrm{mmHg}$, from $132.6 \mathrm{mmHg}$ to $124.8 \mathrm{mmHg}$ (Fig. 4) [38, 39].

Population-wide screening of high BP by law begun in 1960 's; therefore, detection and pharmaceutical treatment of hypertension effectively decreased the prevalence of hypertension especially in elder population. However, as the mean BP decreased in the whole population including the younger generations, such a phenomenon cannot be explained merely by the widespread use of anti-hypertensive agents (e.g. $30 \%$ in
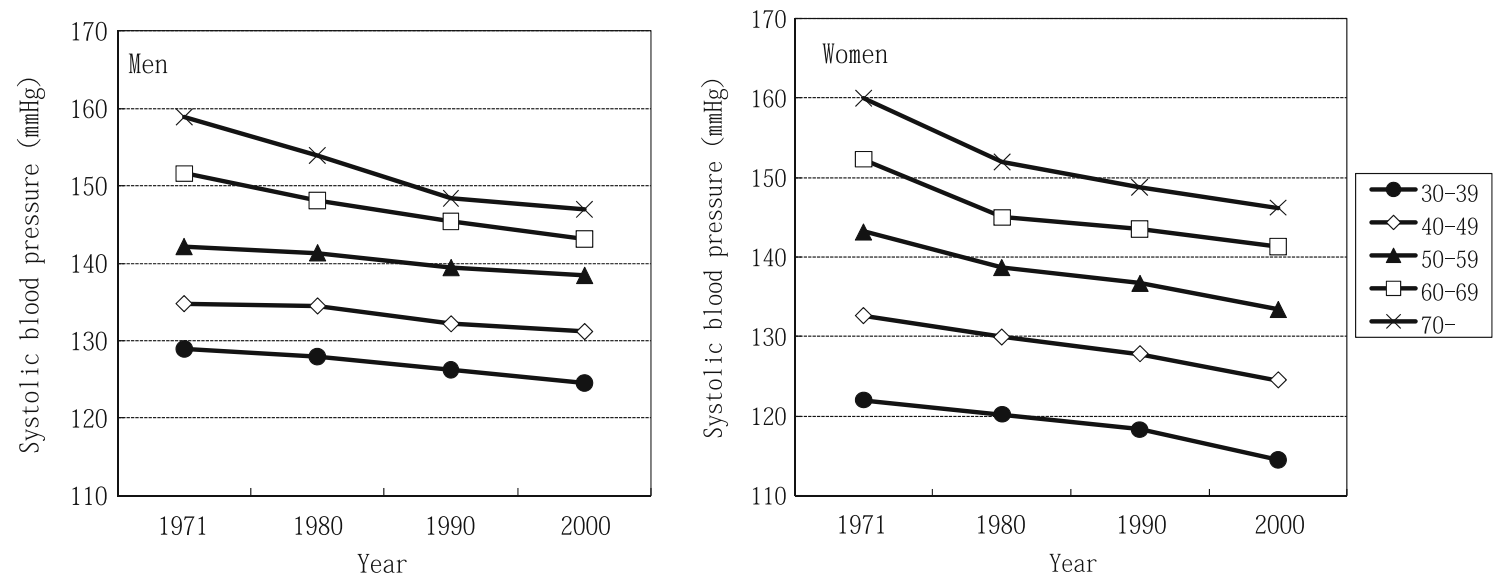

Fig. 4 Trends in mean systolic blood pressure in Japanese men and women by age groups, the National Survey on Circulatory Disorders of Japan (1971-2000) 
1986 to $40 \%$ in 2002 in hypertensive men [40]), but should be largely due to a change in the Japanese lifestyle and dietary habits. BP decreased despite unfavorable trends of other risk factors such as increased obesity (excluding young women) [41] and an increase in alcohol consumption [42]. A reduced consumption of salt would have contributed significantly to this decrease [43]. Several decades ago, people living in the northern part of Japan consumed as much as 20 to $30 \mathrm{~g}$ of salt per day [44]. The National Nutrition Survey reported that the daily salt intake of the Japanese decreased by $3.8 \mathrm{~g}$, from $14.5 \mathrm{~g}$ in 1973 to $10.7 \mathrm{~g}$ in 2009-less than half of the estimated intake in the 1950s [45]. The salt reduction in Japan was accomplished in part by a campaign to reduce salt intake initiated by the Japanese Government in 1960's, in addition to a big lifestyle change during the past several decades. People now do not need to preserve foods using salt through the spread of refrigerator and the development of distribution system, and the westernization of dietary habits reduced the use of soy sauce and miso (fermented soybean paste) which are major dietary sources of salt in Japan.

\section{Concluding remarks and outlook}

Japan is one of the countries with the longest longevity in the world, and it was accomplished by a drastic decline in stroke mortality from 1960's. The decline in stroke mortality would be largely explained by a populationwide decreasing trend in BP level both in men and women in all age-groups, which cannot be fully explained by the widespread use of anti-hypertensive agents. The most probable reason for the population-wide BP decline in Japan would be a large decline in dietary salt intake after 1950's. However, recent increasing trend in obesity, together with high alcohol intake in men, physical inactivity, and unfavorable dietary habits (high energy, high fat, and low vegetable) in Japan could increase BP level of Japanese again. Further continuous efforts for the primary prevention of hypertension are necessary in Japan.

From the experience and epidemiologic findings in Japan, it can be concluded that BP management in individuals and in a whole population is very important to extend longevity. Population-wide screening and early detection of high BP, using both systolic and diastolic BP, are essential, and detected high-risk individuals should modify their lifestyle and, if necessary, should be treated pharmaceutically. On the other hand, population-based approaches to change environments for BP reduction make the individual's effort easier [46, 47]. Such approaches for society, government, manufacturers, communities, worksites, schools, or mass-media should also be applied continuously in future.

\section{References}

1. Stamler J, Stamler R, Neaton JD. Blood pressure, systolic and diastolic, and cardiovascular risks: US population data. Arch Intern Med. 1993;153:598-615.

2. MacMahon S, Peto R, Cutler J, Collins R, Sorlie P, Neaton J, et al. Blood pressure, stroke, and coronary heart disease: part 1, prolonged differences in blood pressure: prospective observation studies corrected for the regression dilution bias. Lancet. 1990;335:765-74.

3. Prospective Studies Collaboration. Age-specific relevance of usual blood pressure to vascular mortality: a meta-analysis of individual data for one million adults in 61 prospective studies. Lancet. 2002;360:1903-13.

4. Asia Pacific Cohort Studies Collaboration. Blood pressure and cardiovascular disease in the Asia Pacific region. J Hypertens. 2003;21:707-16.

5. Ueshima H. Explanation of the Japanese paradox: prevention of increase in coronary heart disease and reduction in stroke. J Atheroscler Thromb. 2007;14:278-86.

6. NIPPON DATA80 Research Group. Risk assessment chart for death from cardiovascular disease based on a 19-year follow-up study of a Japanese representative population: NIPPON DATA80. Circ J. 2006;70:1249-55.

7. NIPPON DATA80 Research Group. Impact of elevated blood pressure on mortality from all causes, cardiovascular diseases, heart disease and stroke among Japanese: 14 year follow-up of randomly selected population from Japanese (Nippon Data80). J Hum Hypertens. 2003;17:851-7.

8. Okayama A, Kadowaki T, Okamura T, Hayakawa T, Ueshima H, DATA80 Research Group. Age-specific effects of systolic and diastolic blood pressures on mortality due to cardiovascular diseases among Japanese men (NIPPON DATA80). J Hypertens. 2006;24:459-62.

9. Hozawa A, Okamura T, Murakami Y, Kadowaki T, Okuda N, Takashima $\mathrm{N}$, et al. High blood pressure in middle age is associated with a future decline in activities of daily living: NIPPON DATA80. J Hum Hypertens. 2009;23:546-52.

10. Murakami Y, Hozawa A, Okamura T, Ueshima H. Relation of blood pressure and all-cause mortality in 180000 Japanese participants: pooled analysis of 13 cohort studies. Hypertension. 2008;51:1-9.

11. Benetos A, Rudnichi A, Safar M, Guize L. Pulse pressure and cardiovascular mortality in normotensive and hypertensive subjects. Hypertension. 1998;32:560-4.

12. Madhavan S, Ooi WL, Cohen H, Alderman MH. Relation of pulse pressure and blood pressure reduction to the incidence of myocardial infarction. Hypertension. 1994;23:395-401.

13. Miura K, Soyama Y, Morikawa Y, Nishijo M, Nakanishi Y, Naruse Y, et al. Comparison of four blood pressure indexes for the prediction of 10-year stroke risk in middle-aged and older Asian. Hypertension. 2004;44:715-20.

14. Asia Pacific Cohort Studies Collaboration. Blood pressure indices and cardiovascular disease in the Asia Pacific region: a pooled analysis. Hypertension. 2003;42:69-75.

15. Japan Arteriosclerosis Longitudinal Study (JALS) Group. Japan arteriosclerosis longitudinal study-existing cohorts combine (JALS-ECC): rationale, design, and population characteristics. Circ J. 2008;72:1563-8.

16. Miura K, Nakagawa H, Ohashi Y, Harada A, Taguri M, Kushiro T, et al. Four blood pressure indices and the risk of stroke and myocardial infarction in Japanese men and women: a meta-analysis of 16 cohort studies. Circulation. 2009;119:1892-8.

17. Dahl LK. Possible role of salt intake in the development of essential hypertension. In: Cottier P, Bock KD, editors. Essential hypertension - an international symposium. Berlin: Springer-Verlag; 1960. p. 53-65. 
18. Intersalt Cooperative Research Group. Intersalt: an international study of electrolyte excretion and blood pressure. Results for 24 hour urinary sodium and potassium excretion. BMJ. 1988;297:31928.

19. Rose G, Stamler J, on behalf of the INTERSALT Co-operative Research Group. The INTERSALT study: background, methods and main results. J Hum Hypertens. 1989;3:283-8.

20. Elliott P, Stamler J, Nichols R, Dyer AR, Stamler R, Kesteloot H, et al. Intersalt revisited: further analyses of 24 hour sodium excretion and blood pressure within and across populations. BMJ. 1996;312:1249-53.

21. Marmot MG, Elliott P, Shipley MJ, Dyer AR, Ueshima H, Beevers DG, et al. Alcohol and blood pressure: the INTERSALT study. BMJ. 1994;308:1263-7.

22. Ueshima H, Shimamoto T, Iida M, Konishi M, Tanigaki M, Doi $\mathrm{M}$, et al. Alcohol intake and hypertension among urban and rural Japanese populations. J Chron Dis. 1984;37:585-92.

23. Iso H, Kitamura A, Shimamoto T, Sankai T, Naito Y, Sato S, et al. Alcohol intake and the risk of cardiovascular disease in middleaged Japanese men. Stroke. 1995;26:767-73.

24. Okamura T, Tanaka T, Yoshita K, Chiba N, Takebayashi T, Kikuchi Y, et al. Specific alcoholic beverage and blood pressure in a middle-aged Japanese population: the High-risk and Population Strategy for Occupational Health Promotion (HIPOP-OHP) Study. J Hum Hypertens. 2004;18:9-16.

25. Yoshita K, Miura K, Morikawa Y, Ishizaki M, Kido T, Naruse Y, et al. Relationship of alcohol consumption to 7 year blood pressure change in Japanese men. J Hypertens. 2005;23:1485-90.

26. Ueshima H, Mikawa K, Baba S, Sasaki S, Ozawa H, Tsushima M, et al. Effect of reduced alcohol consumption on blood pressure in untreated hypertensive men. Hypertension. 1993;21:248-52.

27. Stamler J, Elliott P, Chan Q. INTERMAP appendix tables. J Hum Hypertens. 2003; 17:665-775.

28. Stamler J, Elliott P, Dennis B, Dyer AR, Kesteloot H, Liu K, et al. INTERMAP: background, aims, design, methods, and descriptive statistics (nondietary). J Hum Hypertens. 2003;17:591-608.

29. Dennis B, Stamler J, Buzzard M, Conway R, Elliott P, Moag-Stahlberg A, et al. INTERMAP: The dietary data-Process and quality control. J Hum Hypertens. 2003;17:609-22.

30. Elliott P, Stamler J, Dyer AR, Appel L, Dennis B, Kesteloot H, et al. Association between protein intake and blood pressure: the INTERMAP Study. Arch Intern Med. 2006;166:79-87.

31. Ueshima H, Stamler J, Elliott P, Chan Q, Brown IJ, Carnethon MR, et al. Food omega-3 fatty acid intake of individuals (total, linolenic acid, long-chain) and their blood pressure: INTERMAP study. Hypertension. 2007;50:313-9.

32. Miura K, Stamler J, Nakagawa H, Elliott P, Ueshima H, Chan Q, et al. Relationship of dietary linoleic acid to blood pressure: the International Study of Macro-Micronutrients and Blood Pressure. Hypertension. 2008;52:408-14.
33. Sakurai M, Stamler J, Miura K, Brown IJ, Nakagawa H, Elliott $P$, et al. Relationship of dietary cholesterol to blood pressure: the INTERMAP study. J Hypertens. 2011;29:222-8.

34. Elliott $\mathrm{P}$ et al. Dietary phosphorus and blood pressure: international study of macro- and micro-nutrients and blood pressure. Hypertension. 2008;51:669-75.

35. Tzoulaki I, Brown IJ, Chan Q, Van Horn L, Ueshima H, Zhao L, et al. Relation of iron and red meat intake to blood pressure: cross sectional epidemiological study. BMJ. 2008;337:a258.

36. Stamler J, Brown IJ, Daviglus ML, Chan Q, Kesteloot H, Ueshima $\mathrm{H}$, et al. Glutamic acid, the main dietary amino acid, and blood pressure: the INTERMAP Study. Circulation. 2009;120:221-8.

37. Nakamura K, Okamura T, Hayakawa T, Hozawa A, Kadowaki T, Murakami Y, et al. The proportion of individuals with obesityinduced hypertension among total hypertensives in a general Japanese population: NIPPON DATA80, 90. Eur J Epidemiol. 2007;22:691-8.

38. Sakata K, Labarthe DR. Changes in cardiovascular disease risk factors in three Japanese National Surveys 1971-1990. J Epidemiol. 1996;6:93-107.

39. Ministry of Health, Labour and Welfare. The 5th National Survey of Cardiovascular Diseases. Tokyo: Ministry of Health, Labour and Welfare, Japan; 2002.

40. Ikeda N, Gakidou E, Hasega T, Murray CJL. Understanding the decline of mean systolic blood pressure in Japan: an analysis of pooled data from the National Nutrition Survey, 1986-2002. Bull World Health Organ. 2008;86:978-88.

41. Funatogawa I, Funatogawa T, Nakao M, Karita K, Yano E. Changes in body mass index by birth cohort in Japanese adults: results from the National Nutrition Survey of Japan 1956-2005. Int J Epidemiol. 2009;38:83-92.

42. World Health Organization. Global status report on alcohol and health. Geneva: World Health Organization; 2011.

43. Ueshima H, Tatara K, Asakura S, Okamoto M. Declining trends in blood pressure level and the prevalence of hypertension, and changes in related factors in Japan, 1956-1980. J Chron Dis. 1987:40:137-47.

44. Takahashi E, Sasaki N, Takeda J, et al. The geographic distribution of cerebral hemorrhage and hypertension in Japan. Hum Biol. 1957;29:139-66.

45. Katanoda K, Matsumura Y. National Nutrition Survey in Japan: its methodological transition and current findings. J Nutr Sci Vitaminol. 2002;48:423-32.

46. Welton PK, He J, Appel LJ, Cutler JA, Havas S, Kotchen TA, et al. Primary prevention of hypertension: clinical and public health advisory from the National High Blood Pressure Education Program. JAMA. 2002;288:1882-8.

47. Rose G. The strategy of preventive medicine. New York: Oxford University Press; 1992. 